Acta Technologica Agriculturae 1

Nitra, Slovaca Universitas Agriculturae Nitriae, 2017, pp. 11-18

\title{
THEORETICAL CONSIDERATION OF THE CONTROLLABILITY INDICATOR OF MACHINE-TRACTOR UNIT MOVEMENT
}

\author{
Volodymyr BULGAKOV ${ }^{1}$, Valerii ADAMCHUK ${ }^{2}$, Volodymyr NADYKTO3, \\ Volodymyr KYURCHEV ${ }^{3}$, Ladislav NOZDROVICKY' ${ }^{4 *}$ \\ ${ }^{1}$ National University of Life and Environmental Sciences of Ukraine, Ukraine \\ ${ }^{2}$ National Scientific Centre 'Institute for Agricultural Engineering and Electrification', Ukraine \\ ${ }^{3}$ Tavria State Agrotechnological University of Ukraine, Ukraine \\ ${ }^{4}$ Slovak University of Agriculture in Nitra, Slovak Republic
}

\begin{abstract}
The paper is focused on the issues of controllability of machine-tractor units based on wheel-type tractors during their non-straight driving on the soil surface, which is positioned at an angle to the horizon. There were obtained analytical expressions for the determination of the actual indicator of control $\lambda_{d}$, including both the power and the design parameters of the machine-tractor unit, which affect the abovementioned indicator in the longitudinal vertical plane. These expressions are obtained for the tractor driving on both road and also driving during field operation. In addition, the paper discusses the conditions under which there may occur the cross-slip of the tractor steering wheels in the transversal horizontal plane. As a result of this review, there were obtained the analytical expressions for determining the required indicator of the controllability $\lambda_{d}$ of machine-tractor unit in the horizontal plane, excluding the possibility of lateral sliding of the unit by turning its steering wheels at a certain angle. These expressions are obtained for the two modes of the machine-tractor unit: for driving during transport on the road and during the operation in the field. The machine-tractor unit based on the wheel-type tractor with rear mounted 3-mouldboard plough was analytically investigated. By means of computer calculations, there was observed the fact that when moving in non-straight direction on the soil surface, inclined to the horizon at an angle of $12^{\circ}$, the machine-tractor unit is controllable only when the angles of the steering wheel of the given tractor do not exceed $9^{\circ}$. During the working movement (ploughing) of the given machine-tractor unit on an inclined field surface, its controllability will be preserved on condition that the angle of the tractor steering wheels does not exceed $11^{\circ}$. According to obtained results, it can be stated that the controllability of the machine-tractor unit is determined by the indicator of controllability, taking into account the value of the vertical load acting on the tractor steering wheels, the possibility of their turning in the horizontal plane, as well as the withdrawal of the machine-tractor unit from rectilinear motion and its movement on the field surface, inclined at an angle to the horizon.
\end{abstract}

Keywords: equivalent scheme of forces; equilibrium equations; lifting angle; equivalent wheel, force of inertia; tires diversion

The controllability of machine-tractor units based on wheeltype tractors can be considered one of the basic indicators of their working ability. Scientists have submitted several variants of the methods for evaluation of the machine-tractor unit controllability. In many countries, the controllability evaluation of machine-tractor unit movement is performed by means of indicator $\lambda_{d}$ according to which the load on the tractor steering wheels should reach more than $20 \%$ of operational tractor weight, which means $\lambda_{d} \geq 0.2$ (Farobin, 1970). Páleš et al. (2016) have used B-spline curve to study the vehicle trajectory when moving on a field and they have obtained an exact picture characterizing the movement of the vehicle.

However, in this case, the given evaluation indicator takes into account the state of equilibrium of machine-tractor unit only in the longitudinal vertical plane. In the context of real use, the machine-tractor unit can be climbing on a field with angles $\alpha \geq 12^{\circ}$ and at the same time, the working movement of the machine-tractor unit is accompanied by turns of the steering wheels on headlands at the $\beta$ angles and by the presence of $\delta$ angles of tire slip of its running wheels.

On the other hand, if we estimate the equilibrium conditions of the machine and tractor unit in a longitudinal vertical plane without the parameters $\alpha, \beta$, and $\delta$, then theoretically, the condition $\lambda_{d} \geq 0.2$ can be quite reached. However, in real operating conditions in the presence of the angles $\alpha, \beta$ and $\delta$, this condition is not feasible, and thus one or the tractor units is virtually uncontrollable.

Since the angular parameters $\alpha, \beta$ and $\delta$ have a significant impact on the controllability of machine-tractor unit motion, there is a need for establishing an analytical relationship that will reflect the degree of this influence.

The research of wheel-type tractor controllability, in aggregation with various agricultural machines, was published in many papers, providing detailed information in terms of its balance of longitudinal vertical plane (Severnev, 1982; Guskov et al., 1988; Kutkov, 2004). As a criterion of controllability, there is offered the mentioned indicator 
in studies (Habarta, 1971; Grecenko, 1984; Yisa et al., 1988; Yisa et al., 1995; Yisa et al., 1998); however, the used equations of machine-tractor unit motion on tilted longitudinal vertical plane of the path does not take into account the turning of tractor steering wheels and tires diversion angles of its wheels. When the angles $\alpha$ and $\beta$ are taken into account, the dynamics of machine-tractor unit movement has been studied by many researchers (Habarta, 1971; Grecenko, 1984; Yisa et al. 1995; Stajnko et al., 2012). But considered equations do not take into account the impact of redistribution of the forces that act on the front and rear axles of the tractor wheel in the longitudinal vertical plane. The study of plane motion machine and tractor units on the inclined path is presented by several papers (Sonnen, 1969; Wong et al., 1998; Schreiber and Kutzbach, 2008; Stajnko et al., 2012); however, these papers do not address the criteria for stability of motion similar to criteria $\lambda_{d}$ or others.

\section{Material and methods}

On the basis of theoretical study, the aim is to get new dependencies defining the measure of machinetractor unit controllability, taking into account the influence of the forces acting on it during transport movement on the road and during field operation movement, as well as their structural and kinematic parameters.

Theoretical studies were conducted using the theoretical mechanics methods, the theory of the tractor and the vehicle motion stability theory, programming methods and computer calculations.

\section{Research and discussion}

In order to provide the theoretical research, in the first step, we will use the analytical equation allowing to express the indicator of machinetractor unit controllability $\lambda_{d}$, which can be calculated by using a wellknown equation:

$$
\lambda_{d}=\frac{N_{B}}{G_{t}} \geq 0.2
$$

where:

$N_{B}$ - vertical load acting on the tractor steering wheels

$G_{t}$ - operational tractor weight

However, as mentioned above, condition (1) may be insufficient to ensure a satisfactory controllability of machine-tractor units under certain circumstances. This is especially true when there is a non-rectilinear motion on the field surface, which is inclined at an angle to the horizontal plane. This misalignment of machine-tractor movement is a result of the reaction of tractor control action to the angle of turning of its steering wheels $\beta$.

Consistently, we analytically consider two options of the motion of machine-tractor unit based on a wheel-type tractor (class 1.4) with rear mounted 3-mouldboard plough. The first option involves the movement of the machine in its transport position, the second option during the ploughing process. For each of these scenarios, we will provide an equivalent scheme in the longitudinal vertical plane.

In order to build such equivalent schemes, we will use the schemes that are well known from the theory of tractors and vehicles.

According to the first variant, such a machine-tractor unit performs nonrectilinear transport movement on the soil surface rising at an angle $\alpha$. Its equivalent circuit is shown in Fig. 1. At the same time, to simplify the analytical study as first approximation, we suppose that the contacts of the running wheels of the given tractor with soil occur at points $A$ and $B$.

To compile the necessary equilibrium equations of the above mechanical system in the longitudinal vertical plane, we choose a Cartesian coordinate system $x A y$ with the start at the point $A$ of the contact between the tractor rear wheels and the ground; the horizontal axis $A x$ is directed in the direction of movement of the unit, the $A y$-axis is pointing up, meaning that it is perpendicular to the direction of movement of the machine-tractor unit. Thus, the axis $A x$ also extends at an angle $\alpha$ to the horizontal plane. Presented movement of the machine-tractor unit is effected only by a driving force $\bar{F}_{A}$ of the tractor rear wheels, which is attached at point $A$. When the drive of the front axle of the tractor is turned off, the rolling resistance applied at point $B$ is acting on its steering wheels. The force caused by the tractor weight $\bar{G}_{t}$ is applied to the mass centre of the tractor (point $C$, having coordinates $a_{t}, h_{t}$ ).

In addition, the normal reaction of the soil to the running tractor wheels is displacing on some distance from the points of contact of the tires of its wheels with the ground: from the point $A$, there is shifted reaction $\bar{N}_{A}$ on the distance $a_{z}$ in the direction of travel; and from the point $B$, there is shifted reaction $\bar{N}_{B}$ on the distance $a_{p}$ also in the direction of travel (Fig. 1).

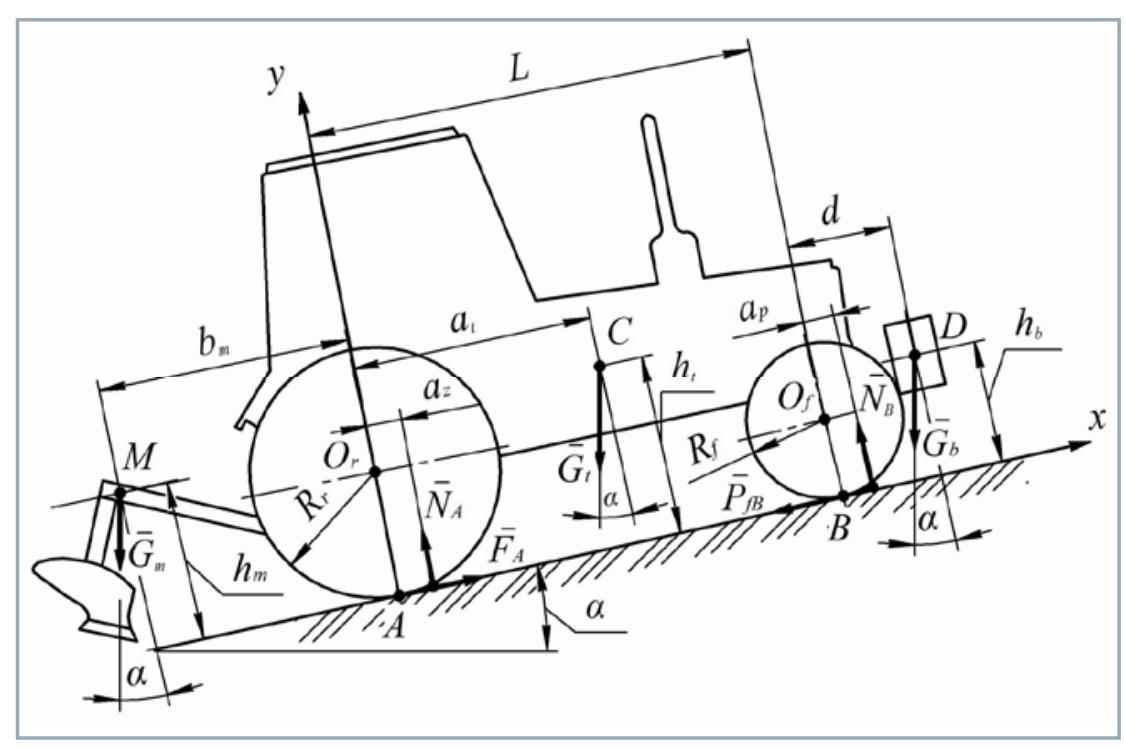

Figure 1 Scheme of the forces acting on the machine-tractor unit during its transport movement on the rise 
The effect of the plough mounted on the wheel-type tractor is represented by the force caused by the weight of the plough $\bar{G}_{m}$, centred in the point $M$ and diverted from the axis $A y$ at an angle $\alpha$, having coordinates $b_{m}$ and $h_{m}$. In addition, it should be noted that the construction of energy unit (wheel-type tractor) is supported by the ballasting of the front axle causing the weight force $\bar{G}_{b}$ centred in the point $D$, having the coordinates $(L+d)$ and $h_{b}$ (Fig. 1).

From all the forces acting on a given machine-tractor unit, there are only two forces which are unknown: normal reaction acting on a tractor front axle $\bar{N}_{B}$ and normal reaction acting on a tractor rear axle $\bar{N}_{A}$. To find them, it is sufficient to prepare the system consisting of two equilibrium equations related to the machine-tractor unit in the form of vanishing of the sum of projections of all forces on the axis $A y$ and the sum of moments of all forces related to the point $A$, and namely:

$$
\left.\begin{array}{c}
\left(G_{t}+G_{b}+G_{m}\right) \cos \alpha-N_{B}-N_{A}=0 \\
G_{t}\left(a_{t} \cos \alpha-h_{t} \sin \alpha\right)-G_{m}\left(b_{m} \cos \alpha+h_{m} \sin \alpha\right)+ \\
+G_{b}\left[(L+d) \cos \alpha-h_{b} \sin \alpha\right]-N_{A} a_{z}-N_{B}\left(L+a_{p}\right)=0
\end{array}\right\}
$$

where:

$L \quad$ - longitudinal tractor wheel base

$a_{p}, a_{z}-$ arms of the acting forces $\bar{N}_{B}$ and $\bar{N}_{A}$ (Fig. 1) step:

The following designations are introduced in the next

$$
\begin{gathered}
K_{1}=G_{t}\left(a_{t} \cos \alpha-h_{t} \sin \alpha\right) \\
K_{2}=G_{m}\left(b_{m} \cos \alpha+h_{m} \sin \alpha\right) \\
K_{3}=G_{b}\left[(L+d) \cos \alpha-h_{b} \sin \alpha\right]
\end{gathered}
$$

Then, after substituting values (3), the system of Eq. (2) takes the following form:

$$
\left.\begin{array}{r}
\left(G_{t}+G_{b}+G_{m}\right) \cos \alpha-N_{B}-N_{A}=0 \\
K_{1}-K_{2}+K_{3}-N_{A} a_{z}-N_{B}\left(L+a_{p}\right)=0
\end{array}\right\}
$$

We are able to determine the reaction force $N_{B}$ from Eq. (4):

$$
N_{B}=\frac{K_{1}-K_{2}+K_{3}-a_{z}\left(G_{t}+G_{b}+G_{m}\right) \cos \alpha}{L-a_{z}-a_{p}}
$$

From the theory of tractor (Kutkov, 2004), it is well known that:

$$
\begin{aligned}
& a_{p}=f_{k} R_{f} \\
& a_{z}=f_{k} R_{r}
\end{aligned}
$$

where:

$$
\begin{aligned}
f_{k}- & \text { rolling resistance coefficient } \\
R_{f} R_{r}- & \text { rolling radius of the front and rear wheels of the } \\
& \text { tractor }
\end{aligned}
$$

By means of Eq. (6), Eq. (5) is transformed to the following form:

$$
N_{B}=\frac{K_{1}-K_{2}+K_{3}-f_{k} R_{r}\left(G_{t}+G_{b}+G_{m}\right) \cos \alpha}{L-f_{k}\left(R_{r}-R_{f}\right)}
$$

With regard to Eq. (1) and (7), the equation for determination of the controllability indicator $\lambda_{d}$ finally takes the following form:

$$
\lambda_{d}=\frac{K_{1}-K_{2}+K_{3}-f_{k} R_{r}\left(G_{t}+G_{b}+G_{m}\right) \cos \alpha}{G_{t}\left[L-f_{k}\left(R_{r}-R_{f}\right)\right]}
$$

Observing the above Eq. (8), we can see that meeting the condition (1) depends on many factors. The force factors $\left(\bar{G}_{t}, \bar{G}_{m}, \bar{G}_{b}\right)$ and design parameters of the machine-tractor unit $\left(a_{t}, b_{m^{\prime}} d, h_{t}, h_{m^{\prime}} h_{b}, L, R_{r}, R_{f}\right)$, as well as conditions of its movement (angle $\alpha$, coefficient $f_{k}$ ) belong to such factors. However, all the mentioned factors realize their influence on the indicator $\lambda_{d}$ only in the longitudinal vertical plane. It must be mentioned that in the curvilinear motion of the machine-tractor unit at a certain value of the reaction $\bar{N}_{B}$ (and hence the indicator $\lambda_{d}$ ), there may occur such unloading of the tractor steering wheels which will cause their cross slide in a horizontal plane. The result is deterioration of both the controllability and stability of machine-tractor unit movement. In general, the machinetractor unit can become uncontrollable under certain conditions.

For further theoretical analysis, we will present the tractor front wheels with one 'equivalent' wheel (Gjachev, 1981; Khvostov and Pozov, 1987; Kasymov and Zolotarev, 1988) disposed in a plane which passes through the longitudinal axis of symmetry of the tractor (Fig. 2a).

We have already emphasized that, from the side of the frame of the tractor, there is a driving force $\bar{F}_{A}$ acting on the tractor front axle. From the equilibrium equation written in the form of vanishing of the sum of projections of all forces on the axis $A x$ (Fig. 1), it follows that this force will be equal to:

$$
F_{A}=\left(G_{t}+G_{b}+G_{m}\right) \sin \alpha+P_{f B}
$$

It should be also emphasized that the projection of the force $\bar{P}_{f B}$ applied at the point $B$ in the horizontal plane is deviating from the longitudinal axis of symmetry of the front 'equivalent' wheel at slip angle $\delta$. In this case, it is determined from this expression:

$$
P_{f B}=f_{k} N_{B}
$$

Accordingly, we obtain the value of the force $F_{A}$ from Eq. (9) and (10):

$$
F_{A}=\left(G_{t}+G_{b}+G_{m}\right) \sin \alpha+f_{k} N_{B}
$$

In the presence of control action - turning of the steering wheels at an angle $\beta$ - the longitudinal component $\bar{F}_{A P}$ of force $\bar{F}_{A}$ pushes the 'equivalent' wheel in the direction 

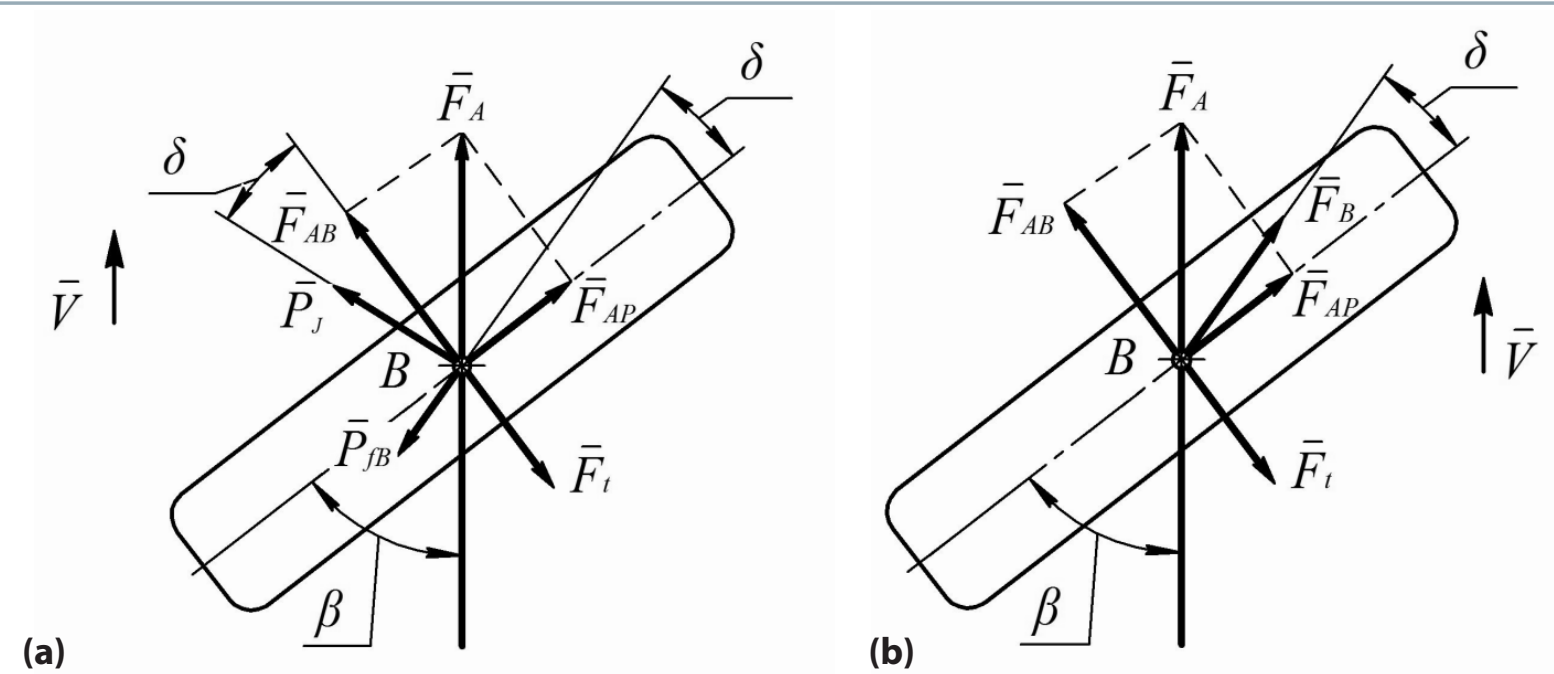

Figure 2 Scheme of the forces acting on the front 'equivalent' wheel of the tractor for its turning angle in the horizontal plane (b) during transport movement (a) and working movement (b) of the machine-tractor unit used for ploughing

of travel; and the transverse component $\bar{F}_{A B}$, with the force of inertia $\bar{P}_{\text {J }}$ of the front axle are trying to direct it sideways (Fig. 2a).

Due to the action of all lateral forces on the 'equivalent' wheel from the ground, there occurs the reaction of friction. As a driving condition for movement of the wheel without cross slip, there is a condition expressed by the following inequality according to the scheme of forces shown in Fig. 2a:

$$
F_{t} \geq F_{A B}-P_{f B} \sin \delta+P_{\jmath} \cos \delta
$$

The reaction of friction $\bar{F}_{t}$ depends on the friction coefficient of the 'equivalent' wheel with the ground $f_{t}$, as well as on the value of vertical load on the tractor steering wheels $\bar{N}_{B}$. Therefore, its value will be equal to:

$$
F_{t}=f_{t} N_{B}
$$

According to the analysis of data given by the force scheme (Fig. 2a), it can be stated that the force $F_{A B}$ will be equal as follows:

$$
F_{A B}=F_{A} \sin \beta
$$

The force of inertia of the front axle of the tractor is defined by the following expression:

$$
P_{J}=\frac{N_{B} V^{2}}{g R_{B}}
$$

where:

$V \quad$ - velocity of movement of the point $B$ (Fig. 2a), which can be accepted with a sufficient degree of accuracy as equal to the forward speed of the machine-tractor unit

$g \quad$ - acceleration of free fall

$R_{B} \quad$ - the turning radius of the front axle of the tractor
According to Farobin (1970), its value will be equal to:

$$
R_{B}=\frac{L}{\sin (\beta+\delta)}
$$

By substituting Eq. (16) into Eq. (15) we get:

$$
P_{J}=\frac{N_{B} V^{2} \sin (\beta+\delta)}{g L}
$$

With regard to Eq. (11), (13), (14) and (17), Eq. (12) will have the following form:

$f_{t} N_{B} \geq \frac{\left(G_{t}+G_{b}+G_{m}\right) \sin \alpha \sin \beta+f_{k} N_{B} \sin \beta-f_{k} N_{B} \sin \delta+N_{B} V^{2} \sin (\beta+\delta)}{L g}$

Solving the inequality (18) in relation to $N_{B}$, we obtain such a value at which the movement of the given 'equivalent' wheel will be without cross slip:

$$
N_{B} \geq \frac{g L\left(G_{t}+G_{b}+G_{m}\right) \sin \alpha \sin \beta}{L g\left[f_{t}-f_{k}(\sin \beta-\sin \delta)\right]-V^{2} \sin (\beta+\delta) \cos \delta}
$$

Dividing both sides of inequality (19) by the force caused by the tractor weight $G_{t}$, we actually receive the value $\lambda_{o}$ :

$\lambda_{o}=\frac{N_{B}}{G_{t}} \geq \frac{g L\left(G_{t}+G_{b}+G_{m}\right) \sin \alpha \sin \beta}{\left\{g L\left[f_{t}-f_{k}(\sin \beta-\sin \delta)\right]-V^{2} \sin (\beta+\delta) \cos \delta\right\} G_{t}}$

Thus, Eq. (8) represents the actual value of the controllability indicator of machine-tractor unit $\lambda_{d}$, and Eq. (20) determines its desired value $\lambda_{o}$. This satisfactory controllability of machine-tractor unit movement will take place only when the following conditions are met:

$$
0<\lambda_{d} \geq \lambda_{o}
$$

We can analyse how the requirements (1) and (21) were considered for a given machine-tractor unit moving in transport mode. At the same time, we perform the numerical 
$\lambda_{d}, \lambda_{o}$

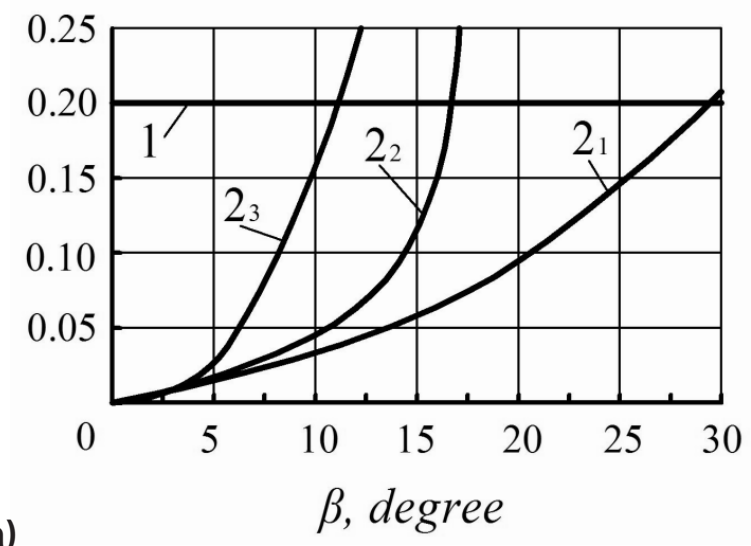

$\lambda_{d}, \lambda_{o}$

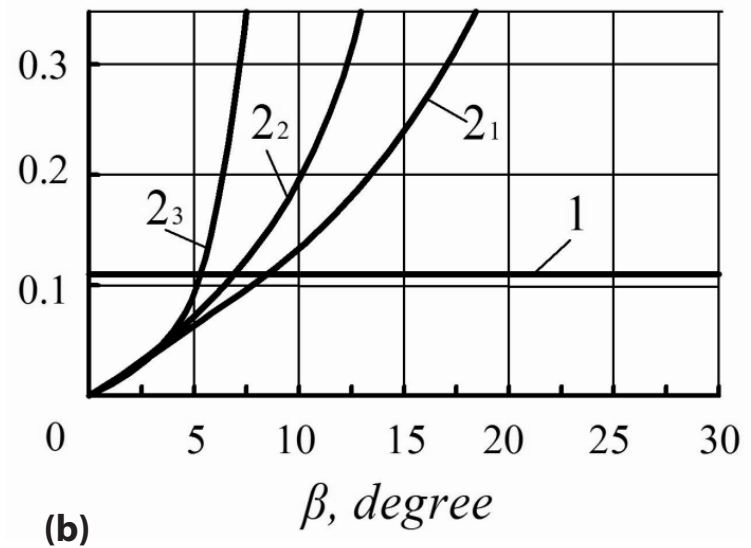

Figure 3 Dependence of the real value $\lambda_{d}$ (curves 1 ) and required value $\lambda_{o}$ (curves 2 ) of the controllability indicator of transport machine-tractor unit at the turning angle $\beta$ of tractor steering wheels at an angle of inclination of the road surface $\alpha=0^{\circ}$ (a) and $\alpha=12^{\circ}(\mathrm{b}): 2_{1}-V=3.5 \mathrm{~m} \mathrm{~s}^{-1} ; 2_{2}-V=5.0 \mathrm{~m} \mathrm{~s}^{-1} ; 2_{3}-V=7.0 \mathrm{~m} \mathrm{~s}^{-1}$

calculations on the $\mathrm{PC}$, and the following values were used as its input design and kinematic parameters: $G_{t}=40 \mathrm{kN}$; $G_{b}=0 ; L=2.45 \mathrm{~m} ; a_{t}=0.82 \mathrm{~m} ; h_{t}=0.9 \mathrm{~m} ; G_{m}=4.5 \mathrm{kN}$; $b_{m}=2.2 \mathrm{~m} ; h_{m}=1.25 \mathrm{~m} ; R_{r}=0.73 \mathrm{~m} ; R_{f}=0.46 \mathrm{~m} ; d=0.7 \mathrm{~m} ;$ $h_{b}=1.0 \mathrm{~m} ; f_{k}=0.12 ; \beta=0-30^{\circ} ; \delta=0.01 \beta ; V=3-7 \mathrm{~m} \mathrm{~s}^{-1}$.

According to numerical calculations processed by a computer with special software, the graphs presenting the dependencies of controllability indicators of the machinetractor unit were produced (Fig. 3).

Calculations have shown that, in some cases, the machine-tractor unit is controllable even in non-straight driving on its way without inclination $(\alpha=0)$ in a longitudinal vertical plane.

It can be stated that at the forward speed $V=3.5 \mathrm{~m} \mathrm{~s}^{-1}$ and lesser, the machine-tractor unit controllability will be preserved within all range of changes of the turning angle $\beta$ of tractor steering wheels (curve 2 , Fig. 3a), as condition (21) is met. At the same time, when moving at the forward speed $5 \mathrm{~m} \mathrm{~s}^{-1}\left(18 \mathrm{~km} \mathrm{~h}^{-1}\right)$, the machine-tractor unit will be controllable only in the case that the turning angle $\beta$ of tractor steering wheels will not exceed $16^{\circ}$ (curve $2_{2}$, Fig. $3 a)$. When the machine-tractor unit would be moving at the forward speed $7 \mathrm{~m} \mathrm{~s}^{-1}\left(25.2 \mathrm{~km} \mathrm{~h}^{-1}\right)$, condition (21) will be respected and the machine-tractor unit controllability will be preserved if the turning angle $\beta$ of tractor steering wheels is varying within the range of $0-11^{\circ}$ (curve $2_{3}$, Fig. $3 a$ ).

Normative documents related to the exploitation of tractors published around the world (Sineokov, 1965) are based on an idea that the tractor as a part of a machinetractor unit is able to steadily overcome the slopes having an inclination not lesser than $\alpha=12^{\circ}$.

In such a case, condition (1) related to straight-line movement is not met for our ploughing machine-tractor unit, as the real value of the indicator $\lambda_{d}=0.11$ (curve 1 , Fig. $3 b$ ) is lower than its normative value. However, a final conclusion on the controllability or uncontrollability of the machine-tractor unit can be done only after checking the condition (21). The calculation based on using the function (20) shows that, for the values of the turning angle $\beta$ of tractor steering wheels up to $8^{\circ}$ and forward speed $V \leq 3.5 \mathrm{~m} \mathrm{~s}^{-1}$, condition (21) is met (curve $2_{1}$, Fig. $3 b$ ). It means that the given machine-tractor unit is controllable. Its controllability will be preserved also at the forward speed $7 \mathrm{~m} \mathrm{~s}^{-1}$, but in such a case, the turning angle $\beta$ of tractor steering wheels must not exceed $5^{\circ}$ (curve $2_{3}$, Fig. $3 \mathrm{~b}$ ).

The ballasting of the tractor front axle belongs to the ways how to solve the mentioned technical problem.

The computer calculation results have made it possible to provide the graphs of values of machine-tractor unit controllability indicators in relation to the value of ballasting of the front axle of the tractor (Fig. 4). It was found that with an increase in the value of the parameter $G_{b}$, the vertical load $N_{b}$ acting on the tractor steering wheels together with the indicator $\lambda_{d}$ are increasing (curve 1, Fig. 4).

The calculations show that, at the same time, the required value of the controllability indicator $\lambda_{o}$ is also increasing. But with different values of forward speed, this increase varies. The analysis of the data presented in Fig. 4 also shows that

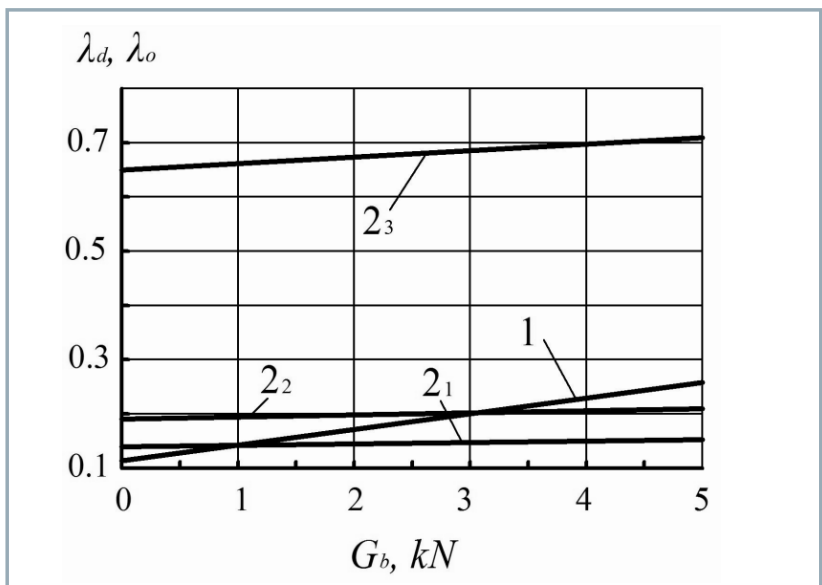

Figure 4 Dependence of the real values $\lambda_{d}$ (curve 1) and required values $\lambda_{o}$ (curves 2 ) of the controllability indicator of machine-tractor unit on the ballasting of the front axle and its forward speed: $\alpha=12^{\circ} ; \beta=10^{\circ} ; 2_{1}-V=3.5 \mathrm{~m} \mathrm{~s}^{-1} ; 2_{2}-V=5.0 \mathrm{~m} \mathrm{~s}^{-1}$; $2_{3}-V=7.0 \mathrm{~m} \mathrm{~s}^{-1}$ 
for $\alpha=12^{\circ}, \beta=10^{\circ}$ and $V=3.5 \mathrm{~m} \mathrm{~s}^{-1}$, condition (21) can be met when the value of ballast is $G_{b} \geq 1 \mathrm{kN}$. The weight of ballast will be $G_{b}=1,020 \mathrm{~kg}$ in such a case.

If the machine-tractor unit moves at the forward speed $5 \mathrm{~m} \mathrm{~s}^{-1}$, the equality of the real value $\lambda_{d}$ (curve 1, Fig. 4) and the required value $\lambda_{0}$ (curve $2_{2}$, Fig. 4) of controllability indicator will be reached at the weight of ballast $3 \mathrm{kN}$ (the weight of ballast will be $G_{b}=3,060 \mathrm{~kg}$ ).

Simultaneously, for the controllable (and thus stable) motion of the considered machine-tractor unit at a speed of $7 \mathrm{~m} \mathrm{~s}^{-1}\left(25.2 \mathrm{~km} \mathrm{~h}^{-1}\right)$, condition (21) will be met only when ballasting of the front axle of the tractor is $G_{b}=33 \mathrm{kN}$ (ballast weight is equal to $G_{b}=3,364 \mathrm{~kg}$ ). It is clear that it is impossible to place such a weight of ballast on the front axle of the wheel tractor of category 1.4.

It follows that the use of ballasting of the front axle of some wheel-type tractor steering wheels allows solving the problem of controllability during the non-rectilinear motion of the machine-tractor unit only for certain forward speed range.

In the next step, we will study the variant of machinetractor unit movement during the ploughing operation. In order to secure a lower slippage of the tractor wheels in such a case, it is useful to turn on the front axle drive.

In the balance of the forces acting on the machinetractor unit, there will be some change - the driving force $\bar{F}_{B}$, instead of force representing the resistance force $\bar{P}_{f B}$, will be acting in the same point $B$ (Fig. 2b).

The forward speed of the machine-tractor unit during ploughing usually varies within the range of $2.0-2.5 \mathrm{~m} \mathrm{~s}^{-1}$. Because of this, the force of inertia of the front axle $\bar{P}_{J}$ (Fig. 2a), manifesting itself during the steering of the tractor steering wheels at an angle $\beta$, can be neglected.

In Fig. 5, there is presented the equivalent scheme for the case of machine-tractor unit working movement during ploughing. There will be made some change in this schemeinstead of movement resistance force $\bar{P}_{f B}$, the driving force $\bar{F}_{B}$ will be acting in the same point $B$. In addition to this, instead of the force $\bar{G}_{m}$ acting in the point $M$, the force of pulling resistance $\bar{P}_{k r}$ of the 3-mouldboard plough is shown in the scheme. Other external force influences are similar to the previous equivalent scheme shown in Fig. 1.

The results of experimental research have confirmed that the force of resistance $\bar{P}_{k r}$ of the 3-mouldboard plough can reach $12 \mathrm{kN}$ (as mean value) during ploughing at the depth of $25-27 \mathrm{~cm}$. The angle $\gamma$ of inclination of this force to the plane of movement is $\gamma \approx 6^{\circ}$, the component of its actions in relation to the point $A$ (Fig. 5) is $h_{m} \approx 0.15 \mathrm{~m}$ (Kasymov and Zolotarev, 1988).

In order to determine the real value of the controllability indicator $\lambda_{d}$, we compile up the equations of equilibrium according to the main scheme (Fig. 5) in the form of vanishing of the sum of projections of all forces on the axis $A y$ and the sum of moments of all forces related to the point $A$, namely:

$$
\begin{gathered}
\left(G_{t}+G_{b}\right) \cos \alpha+P_{k r} \sin \gamma-N_{B}-N_{A}=0 \\
G_{t}\left(a_{t} \cos \alpha-h_{t} \sin \alpha\right)-P_{k r} h_{m}+G_{b}\left[(L+d) \cos \alpha-h_{b} \sin \alpha\right]- \\
-N_{A} a_{z}-N_{b}\left(L+a_{p}\right)=0
\end{gathered}
$$

To earlier accepted designations (3) we add another following designation:

$$
K_{4}=-P_{k r} h_{m}
$$

In regards to all accepted designations (3) and (23), the system of equilibrium Eq. (22) will take the following form:

$$
\left.\begin{array}{c}
\left(G_{t}+G_{b}\right) \cos \alpha+P_{k r} \sin \gamma-N_{B}-N_{A}=0 \\
K_{1}+K_{3}+K_{4}-N_{A} a_{z}-N_{b}\left(L+a_{p}\right)=0
\end{array}\right\}
$$

In the system of Eq. (24), we find:

$$
N_{B}=\frac{K_{1}+K_{3}+K_{4}-\left[\left(G_{t}+G_{b}\right) \cos \alpha+P_{k r} \sin \gamma\right] a_{z}}{L-a_{z}+a_{p}}
$$
form:

Using expression (6), Eq. (25) takes the following

$$
N_{B}=\frac{K_{1}+K_{3}+K_{4}-\left[\left(G_{t}+G_{b}\right) \cos \alpha+P_{k r} \sin \gamma\right] f_{k} R_{z}}{L-f_{k}\left(R_{z}-R_{p}\right)}
$$

With regard to expression (1) and Eq. (26), we obtain the real value of the controllability indicator $\lambda_{d}$ from the following equation:

$$
\lambda_{d}=\frac{K_{1}+K_{3}+K_{4}-f_{k} R_{z}\left[\left(G_{t}+G_{b}\right) \cos \alpha+P_{k r} \sin \gamma\right]}{G_{t}\left[L-f_{k}\left(R_{z}-R_{p}\right)\right]}
$$

As it is clear from the analysis of Fig. 2b, Eq. (12) will be changed and it will obtain the following form:

$$
F_{t} \geq F_{A} \sin \beta+F_{B} \sin \delta
$$

According to the results obtained from experiments, it can be stated that during the process of working movementwhen the machine-tractor unit was ploughing - the turning angle $\beta$ of the tractor steering wheels was varying within the range of $0-6^{\circ}$. The angle $\delta$ of tire deflection on the tractor front wheels was also varying at approximately the same range. In the first approximation, it gives the base for assuming that $\delta \approx \beta$.

In regards to the abovementioned facts, condition (28) can be written as:

$$
F_{t} \geq\left(F_{A}+F_{B}\right) \sin \beta
$$

From the equilibrium equation written in the form of vanishing of the sum of projections of all forces on the axis $A x$ (Fig. 5), we obtain the following expression:

$$
F_{A}+F_{B}=\left(G_{t}+G_{b}\right) \sin \alpha+P_{k r} \cos \gamma
$$

Taking into account the expression (13), (29) and (30), we obtain:

$$
N_{B} \geq \frac{\left[\left(G_{t}+G_{b}\right) \sin \alpha+P_{k r} \cos \gamma\right] \sin \beta}{f_{t}}
$$




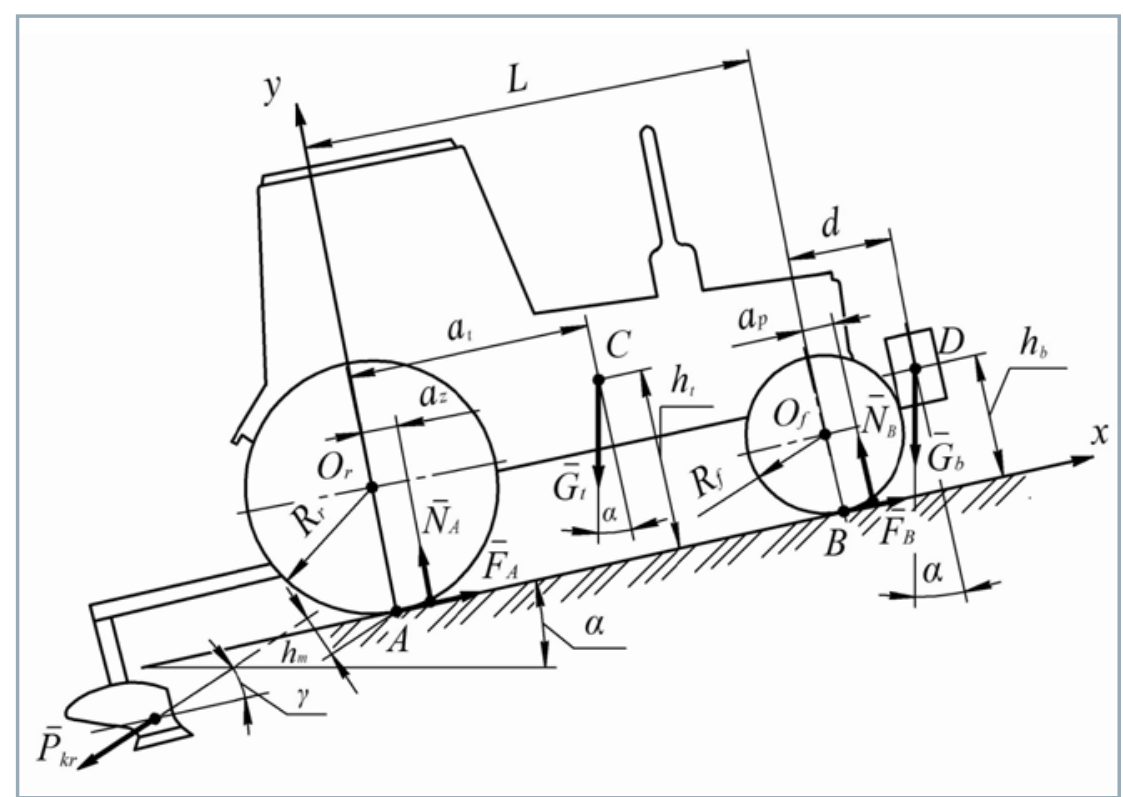

Figure 5 Scheme of the driving forces which act on the machine-tractor unit during its working movement on the rise

Dividing both sides of non-equilibrium Eq. (31) by the force $G_{t}$ caused by the tractor weight, and with the regard to Eq. (1), we obtain an expression for determining the desired value of the indicator of controllability $\lambda_{d}$ of machinetractor unit movement during ploughing in the following form:

$$
\lambda_{o}=\frac{N_{B}}{G_{t}} \geq \frac{\left[\left(G_{t}+G_{b}\right) \sin \alpha+P_{k r} \cos \gamma\right] \sin \beta}{f_{t} G_{t}}
$$

Numerical calculations carried out by a computer show that during the working movement of the machine-tractor unit when ploughing on the site without inclination ( $\alpha=0$ ), condition (1) is completely met, as the value of $\lambda_{d}$ determined by expression (27) is 0.28 (Fig. 6a). Condition (21) is met when the angle $\beta$ of deflection of the tractor steering wheels does not exceed $25^{\circ}$. In order to obtain the machine-tractor unit controllability in the case when $\beta=30^{\circ}$, it is necessary to ballast the tractor front axle by the ballast having a weight of $200 \mathrm{~kg}$, which is quite realistic.

If the machine-tractor unit moves in the field with an inclination of $12^{\circ}$, condition (21) is valid for the angle $\beta$ not exceeding the value $11^{\circ}$ (Fig. 6b). In order to meet the above condition in the case when $\beta=30^{\circ}$, the tractor front axle must be ballasted by the ballast weight of at least $1,530 \mathrm{~kg}$. It is not technically possible for the wheeltype tractor of category 1.4.

However, it is not necessary to do it in practice, since, as noted above, the angle $\beta$ of the tractor steering wheels varies within the range of $0-6^{\circ}$. It means that even on inclined surface of the field within the range of the angle $\alpha=0-12^{\circ}$, the working movement of the ploughing machine-tractor unit will be fully controllable.

\section{Conclusion}

1. To analyse the machine-tractor unit controllability, the indicator taking into account not only the value of the vertical load acting on the tractor steering wheels, but also the possibility of their turning, as well as displacement during the deviation of the machine-tractor unit from rectilinear motion and its moving at an angle to the horizontal plane can be used.

2. There were obtained analytical Eq. (20) and (32), allowing us to determine the controllability indicator of the machine tractor unit. Equations (20) and (32) describe the relationship between the abovementioned factors.

3. Machine-tractor unit controllability can be considered as acceptable if the real values of the controllability indicator, calculated according to Eq. (8) and (27), and the required values of the controllability $\lambda_{d}, \lambda_{o}$

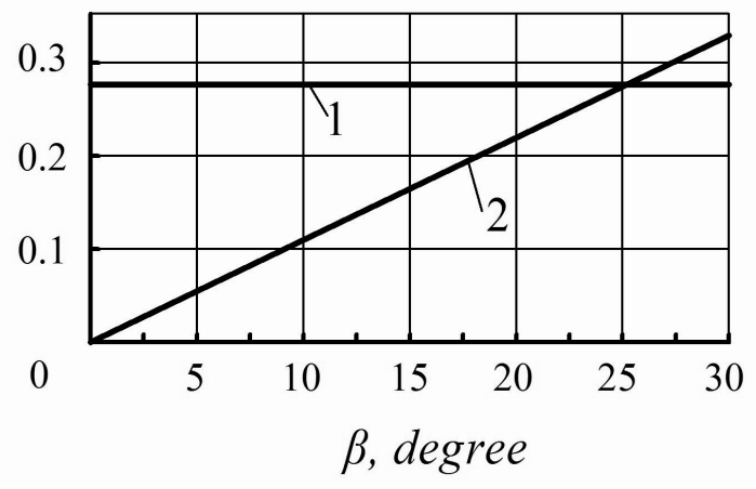

(a)

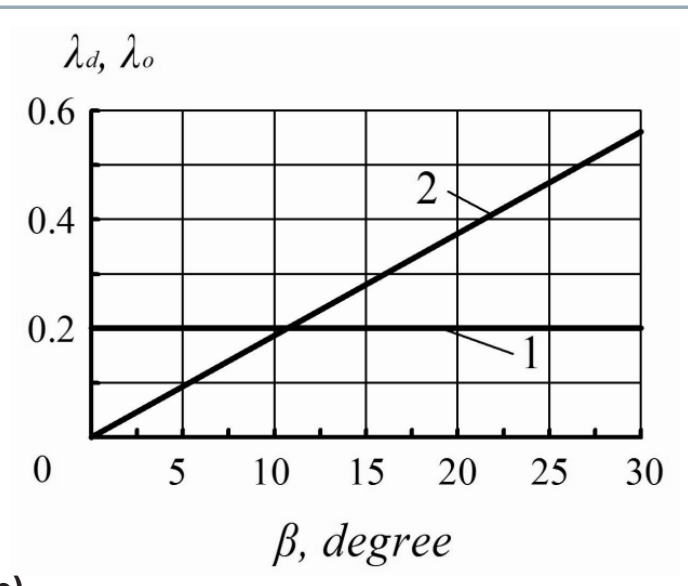

(b)

Figure 6 Dependency of the real value $\lambda_{d}-1$ and required value $\lambda_{o}-2$ of the controllability indicator of the ploughing machine-tractor unit on the angle $\beta$ of deflection of the tractor steering wheels for the angle of field inclination $\alpha$ : $\alpha=0^{\circ}(\mathrm{a})$ and $\alpha=12^{\circ}(\mathrm{b})$ 
indicator, calculated according to Eq. (20) and (32), meet the condition (21).

\section{References}

FAROBIN, A. Ja. 1970. Theory of Turning of Transport Machines. Moscow : Mashinostrojenie, 1970. 174 pp.

GJACHEV, L.V. 1981. Stability of Motion of Agricultural Machines and Machine-Tractor Units. Moscow : Mashinostrojenie, 1981. 206 pp.

GRECENKO, A. 1984. Operation on steep slopes. State-of-theArt Report. In Journal of Terramechanics, vol. 21, 1984, no. 2, pp. 181-194.

GUSKOV, V. V. - VELEV, N. N. - ATAMANOV, Ju. E. et al. 1988. Tractors: Theory. Moscow : Mashinostroenie, 1988. 376 pp.

HABARTA, F. 1971. Determination in relation to safety of operation of the minimal load on the front steering axle of a tractor with implements attached. In Journal of Agricultural Engineering Research, vol. 16, 1971, no. 2, pp. 126-140.

KASYMOV, A. SH. - ZOLOTAREV, V. V. 1988. Steady rectilinear motion of arable unit with front and rear linkage. In Traktory i selskokhozjajstvennyie mashiny, 1988, no. 1, pp. 13-18.

KHVOSTOV, V. A. - POZOV, N. V. 1987. Dynamics of self-propelled three-axle machine unit for tilled crops. In Traktory i selkhozmashiny, 1987, no. 4, pp. 24-28.

KUTKOV, G. M. 2004. Tractors and Lorries. Theory and Technological Properties. Moscow : Kolos, 2004. 504 pp.

PÁLEŠ, D. - VÁLIKOVÁ, V. - ANTL, J. - TÓTH, F. 2016. Approximation of vehicle trajectory with B-spline curve. In Acta Technologica Agriculturae, vol. 19, 2016, no. 1, pp. 1-5.

SCHREIBER, M. - KUTZBACH, H. 2008. Influence of soil and tire parameters on traction. In Research in Agricultural Engineering, vol. 54,2008 , no. 2 , pp. $43-49$.
SEVERNEV, M. M. 1982. Perspective mobile energy means for agricultural production. Minsk: Nauka i tekhnika, 1982. 272 pp. SINEOKOV, G. N. 1965. Designing of Soil Tillage Machines. Moscow : Mashinostrojenie, $1965.312 \mathrm{pp}$.

SONNEN, F. J. 1969. Drawbar performance of high-powered farm tractors with rear-wheel and four-wheel drive. In Journal of Terramechanics, vol. 6, 1969, no. 1, pp. 7-21.

STAJNKO, D. - BERG, R. - MURSEC, V. - VINDIS, R. 2012. The influence of different steering systems on a wheel slip. In Journal of Achievements in Materials and Manufacturing Engineering, vol. 55, 2012, no. 2, pp. 76-85.

WONG, J. Y. - MCLAUGHLIN, N. B. - KNEZEVIC, Z. - BURTT, S. 1998 Optimization of the tractive performance of four-wheel-drive tractors: Theoretical analysis and experimental substantiation. In Journal of Automobile Engineering, vol. 212, 1998, no. 4, pp. 285-297.

YISA, M. G. - TERANO, H. - NOGUCHI, N. - KUBOTA, M. 1988. Stability criteria for tractor-implement operation on slopes. In Journal of Terramechanics, vol. 35, 1988, no. 1, pp. 1-19.

YISA, M. G. - TERANO, H. 1995. Dynamics of tractor-implement combinations on slopes (Part I). State-of-the-art Review. In Journal of the Faculty of Agriculture, Hokkaido University, vol. 66, 1995, no. 2, pp. 240-262.

YISA, M. G. - TERANO, H. - NOGUCHI, N. - KUBOTA, M. 1998 Dynamics of tractor-implement combinations on slopes. (Part III), Stability Regions and Optimum Design Parameters. In Journal of the Faculty Agriculture, Hokkaido University, vol. 68, 1998, no. 1, pp. 1-16. 